WellBeing International

WBI Studies Repository

1982

\title{
Genetic Adaptation in Relation to Animal Welfare
}

R. G. Beilharz

University of Melbourne

Follow this and additional works at: https://www.wellbeingintlstudiesrepository.org/acwp_gem

Part of the Animal Studies Commons, Other Animal Sciences Commons, and the Other Genetics and Genomics Commons

\section{Recommended Citation}

Beilharz, R.G. (1982). Genetic adaptation in relation to animal welfare. International Journal for the Study of Animal Problems, 3(2), 117-124.

This material is brought to you for free and open access by WellBeing International. It has been accepted for inclusion by an authorized administrator of the WBI Studies Repository. For more information, please contact wbisr-info@wellbeingintl.org.

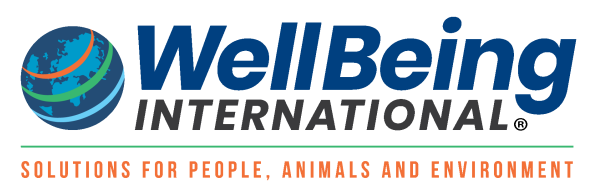




\title{
Comments
}

\section{Genetic Adaptation in Relation to Animal Welfare}

\author{
R.G. Beilharz
}

\section{Introduction}

In this essay I outline the processes of adaptation of animals and of animal populations and discuss their relevance to the problem of animal welfare. Because "animal welfare" has many different aspects including philosophical, ethical, and biological, it is important to examine some of the fundamental issues that underly the concept. Hence, in this essay, I comment on how people come to "know," how information accumulates, and how what we know influences our actions. I also discuss the biological information that is relevant to animal welfare. It is my hope that, when this topic has been placed within a broader framework of this sort, more generally useful solutions to the "animal welfare problem" may be found.

\section{What Is Adaptation?}

The theory of evolution has become the unifying explanation underlying the whole of biology. Dobzhansky et al. (1977) summarize the concept of evolution by natural selection as follows: "Among alternative genetic variants, some result in features that are useful to their carriers as adaptations to the environment. Individuals possessing useful adaptations are likely to leave, on the average, greater numbers of progeny than individuals lacking them (or having less useful adaptations). Therefore use- ful adaptations become established in populations.... Adaptations can be recognized in individuals - whether physiological, morphological, behavioral-as well as [at] the level of the population." At the level of the population, such adaptation is the result of changing gene frequencies. At the level of the individual, adaptation is the adjustment of the individual to its environment, within the scope of the developmental possibilities allowed by its genetic blueprint.

Organisms are complex, and genes interact with many other genes as well as the environment in the process of guiding the development of an organism. While the science of quantitative genetics recognizes interactions in its explanatory model, the model is usually expressed in terms of variation of the trait at a particular point in the life cycle, e.g., the weight at 9 weeks, or "production" at maturity. I suggest that this focus on a point in the life cycle has not allowed the full explanatory potential of quantitative genetics to be realized.

One aspect of variation, including genetic variation, in growth and development concerns the degree of flexibility of the developmental path. Rendel's (1967) elaboration of Waddington's concept of canalization of development discusses this aspect in detail. In a consideration of behavioral traits, the ideas of "instinctive" behavior (that is, behavior that is programmed via genetically

R.C. Beilharz is a Professor in the School of Agriculture and Forestry, University of Melbourne, Parkville 3052, Victoria, Australia. 
determined neural pathways) and learned behavior (behavior shaped separately in each individual by its particular experience during development) are pertinent to the concept of flexibility of development.

The important point to make is that, in evolution, the genes providing those ontogenetic pathways that are most appropriate for the particular environment will be selected. Thus, constant environments, or recurring stimuli that always require a constant response, will favor selection for an invariable response (which has often been termed instinctive behavior). In contrast, variable, unpredictable environments will favor selection for a flexible path of development, in which individual learning becomes important. Different degrees of variability of the environment will select for different amounts of learning, and the things that are readily learned will be found to be the responses to particular, important stimuli. The amount of variation among these responses is important for the survival of members of the species.

When development is seen in this way, it is clear that when animals are put into a new environment, individuals of some populations and species will be able to adapt their behavior phenotypically by learning. Other species will not be able to cope and will show stress. McBride's (1980) model illustrates this phenomenon well. Where individuals do not have the capacity to adjust phenotypically, adaptation of the population will require a rapid genetic response to prevent the dying out of the population. Such a process of adaptation is likely to be accompanied by much "suffering." By contrast, where phenotypic adjustment is possible, each individual can adapt and there may be little "suffering." To the extent that some individuals do suffer, this implies that some are not able to handle the new environment as well as others, and as McBride (1980) suggested, genetic adaptation will still occur at the population level.

We can summarize the process of genetic adaptation by endorsing McBride's model. In any defined environment, selection of appropriate developmental paths will occur, usually accompanied by a genetic response. This process is inevitable and will proceed to the point where the majority of individuals cope adequately with the environment.

In particular, domestication has been a special type of evolutionary process that has resulted in the adaptation of animals to environments specified by man. As man intensifies the conditions under which animals are kept, further selection is taking place. We must now consider how adaptation is relevant to animal welfare.

\section{How Is Adaptation Relevant to Welfare?}

"Problems" in animal welfare derive at least in part from the fact that animal welfare has been approached from the points of view of many very different belief systems. A traditional Christian belief has been that man, made in the image of God, has control over all the rest of creation. A radically different belief, common among Hindus and Buddhists, is that animals and man are fellow creatures, thereby implying no rights of man over animals. Singer (1975) argues as a philosopher and supplies the intellectual underpinning for Australia's animal welfare movement, which sets out to defend the rights of animals against exploitation by man. Ethologists approach animal welfare from the point of view of a natural science (e.g., Beilharz and Zeeb, 1981). I strongly believe that the differing backgrounds of the persons who argue for and against animal welfare are the underlying cause of many of the "problems" of animal welfare. Is it 
possible to find a common ground? To try to do so, we must first ask some very basic questions.

\section{Why, and What, Do People "Know"?}

One process by which humans accumulate knowledge (albeit limited) about reality occurs via the so-called scientific method. The scientific method consists of (1) formulation of models such as axioms, theories, and hypotheses, and (2) testing of these models against reality by means of experiments or other forms of objective observation and measurement. If observation discloses a discrepancy between the model and our preconceived reality, the model is altered. This procedure represents an advance, because an error has been eliminated. However, one can never prove that the model is true. One can only change those parts of it that appear to be wrong and hope that the changed model is a better representation of reality.

Man's everyday knowledge is adjusted to reality in a similar way, although no deliberate effort is made at objective testing of explanatory models. There are, however, areas of "knowledge" or "belief" in which objective testing seems impossible. These areas, e.g., the existence of an afterlife or the existence of God, are said by many to be outside the realm of science because there seems to be no objective way to discriminate among the different explanatory models. But people still have explanatory models in these areas, which are termed "belief" or "faith" and which vary widely.

In this discussion, I am not making any value judgments about the scientific method, on the one hand, and religious belief on the other. I am simply pointing out why, when tests against reality are easily available, most people will believe the same "facts." But this same unanimity is not to be expected in those fields of knowledge where tests against reality are not readily available. In such areas a tolerant examination of many different explanatory models (beliefs) seems to be the most reasonable thing to do.

We may take the models underlying Singer's (1975) philosophy as examples. I can summarize and comment on this philosophy as follows:

1. Singer recognizes that there is a widespread prejudice, which he calls "speciesism," that causes humans to favor the interests of humans over those of animals.

2. Singer states that, by analogy with racism and sexism, this prejudice of speciesism is unjustified. He asserts we should reject all such prejudices and adopt the principle of equal consideration of (varying) interests. He derives from this the idea that humans have no right to utilize animals for their own ends. I comment that this is an example of a postulate (an explanatory model and its consequences) that Singer is making here. Other postulates are also possible, e.g., that, because people have the capacity for "imaginative anticipation" and we assume animals do not, we should consider people's rights above those of animals.

3. Singer continues his argument with the assertion that cruelty, pain, and suffering should be eliminated whenever possible. This is another postulate, but one which 1 and most people will wish to accept. For me the interesting question is, How do we know when animals are suffering or in pain?

4. Singer recognizes that killing of animals is a different problem from that of causing them pain. I comment that if, as suggested in item 2, the principle of equality, or rejection of speciesism, is not the only possible starting point, a conclusion different from the one that humans may not kill and utilize animals may legitimately follow, even though we may agree completely with Singer about 
elimination of cruelty (as summarized in item 3).

Postulates such as Singer's principle of equality are models of how we should behave and seem to reside in the realm of belief, outside the realm of science. Many other postulates can be devised that seem equally plausible in the absence of any objective check against reality. In fact, people often make "moral" judgments based on untestable "religious" convictions. Here again, I make no value judgments. I have simply tried to describe the problem facing us. The next section attempts to find the answer.

\section{How Do People Judge Whether a} Particular Model Is "Cood" or "Right"?

I believe that there is no ultimate external standard to help us answer this question. Each individual will have his own model of the "ultimate" truth, and "purpose," for his life. I thus accept the fact that there will always be varying views among people about a problem such as animal welfare. However, varying views of its members will not prevent a society as a whole from taking action. In practice, it is usually political action that shapes what a society does and that governs the selection of postulates a society uses as its guidelines for behavior. Duncan (1980) has recognized clearly that "decisions on the degree to which, and the manner in which, we [humans] exploit animals are ethical decisions which should be made by society in general but only when they have a knowledge of facts." In the animal welfare debate in West Germany, Wickler (1980) argues that humans cannot know what the real interests of animals are and that what enacted legislation actually ends up protecting is (some) people's interests in animals, not the interests of the animal itself. This statement, like Duncan's, clearly places the animal welfare question within the political or ethical sphere.

It seems rational to recognize this state of affairs. It must also be accepted that, concerning the question of "animal welfare," a knowledge of evolution and how animals adapt to their environment is also very relevant.

\section{What Is Reality, Relevant to Living Things?}

All forms of life survive and develop by utilizing other forms of life, such as food or prey species, predators, parasites, and symbionts. A recent trend in evolutionary thinking (e.g., R. Dawkins, 1976) has focused our attention on the fact that the ruthless exploitation of other life forms may well take place at the level of the individual, or even at the level of the gene, rather than at the level of the species. For us, it is important to note that utilization of other life forms has been the natural commonplace throughout the development of life on earth. Again, without making any value judgments, we can accept this as a neutral fact about the real world around us.

It follows that humans are in no way odd in utilizing other forms of life for their own good. In fact, if we could free ourselves of our human prejudices and take a broad perspective, we would find that in evolution, the interaction of domestic animals with humans has been a very successful form of symbiosis, because neither humans nor domestic animals would be present in the same huge numbers without the other (Elton, 1958; Zeuner, 1963). To me it makes no sense to talk about "rights" of domestic animals, other than in this specific context of their symbiosis with humans. If humans had not been present, there would be no domestic animals about whose rights we could argue. Please note that I am not, here, claiming that we have a right to misuse domestic animals. I simply maintain that it is not in accord with reality to even imagine, far less to give 
rights to, domestic animals under any circumstances other than in their association with humans.

Thus, that part of Singer's postulate which deals with humans' utilization of other animals is not in accord with the reality of life as it has developed on earth. Man is speciesist, and so is every other species. If humans were to act on Singer's postulate of equality, they would be imposing on themselves a new restriction for which there is no justification anywhere in the real world. Clearly, humans are omnivores adapted to eating meat, as well as many other foods. Their pet dogs and cats are carnivores. Some animal welfare literature has suggested that even these pets should be fed without meat. This would of course be completely counter to evolutionary adaptations. As will become clear below, I agree that we can go against particular evolutionary trends and adapt ourselves, as well as our cats and dogs, to eating vegetable matter only, although there has been some disquiet expressed recently in the medical literature about the effects of vegetarian diets on the development of small children (Anonymous, 1978; Shull et al., 1977; Tripp et al., 1979). But such a step is completely unnecessary; I do not think that there is a compelling reason of any sort to suggest that we should not utilize animals or eat their flesh.

\section{What Is Cruelty?}

While we can all agree that cruelty, pain, and suffering should be avoided whenever possible, there may be many situations where there will be doubt about whether cruelty exists.

How can we judge whether an animal in a confined space is suffering? Beilharz and Zeeb (1981) have shown that it is very difficult to demonstrate that apparently healthy animals are suffering, even when kept in small confined spaces. Explanatory models of instinctive behav- ior (e.g., Lorenz, 1978; Manning, 1979) vary, and they do not allow one to argue, on the basis of variations in frequencies of behavior observed under different conditions, that behavioral frustration in any environment necessarily leads to suffering. Similarly, offering animals a choice between environments gives inconclusive results. With appropriate rearing and prior experience almost any familiar environment will be preferred over other environments ( $M$. Dawkins, 1976). Wickler (1980) suggested that the best indicators of variation in welfare are symptoms of stress (physiologically defined), together with observable searching movements or goal-directed striving in particular situations. Such symptoms, as well as manifest injuries, indicate that the animals are not adapted to their situation. McBride's (1980) model is also relevant, suggesting that animals showing the exhaustion phase of the General Adaptation Syndrome, i.e., severe physiological strain, failure to reproduce, and death, are clearly suffering in their environment.

What can we say about free-ranging domestic animals, or wild animals in their natural habitat? In discussing this issue, I find it useful to consider an extreme environment such as a desert. Although humans and most other mammals and birds suffer stress, often to the point of death, in the central area of Australia, there are mammals such as the mulgara (Dasycercus cristicaudata) (Ride, 1970) that are found only in this region. The mulgara has physiological adaptations that allow it to exist without drinking water (it gets it from the meat it eats) and kidneys which are so efficient that it can excrete the large amount of urea produced as a by-product of its diet in a highly concentrated form. As one of its behavioral adaptations, it avoids heat by remaining underground during the day. Presumably such species enjoy an 
advantage gained from the reduced competition found in such a difficult environment. But are they suffering? I believe that we can do no better than to assume that the welfare of any adapted form of life is guaranteed, i.e., that it does not "suffer" in its particular environment.

Domestication is an evolutionary process in which plants and animals continually adapt their genotypes to the environment and the demands created by man. As a result, domestic animals are now very different from their wild ancestor species. And there is no evidence to suggest that domestic animals have lost the power to adapt further. We must therefore expect further changes, including some that will help our animals adjust to intensive conditions, such as cages for hens. From the welfare point of view, the important adaptive changes are those related to the performance of instinctive behavior, which is mainly under genetic control. While morphological structures evolve relatively slowly, the levels of motivation and the threshold values of releasing stimuli are continually adjusted during evolution, so that behavior is appropriate to the environment (Mayr, 1963). The resulting changes in frequency of appearance of behaviors are important in the adaptation of animals during domestication.

Stress symptoms, inappropriate behavior, resulting injury, and lowered "production," particularly as these relate to survival and reproduction, must be expected when animals are first placed in environments to which they are not adapted. A period of adaptation, as discussed earlier, follows unless we prevent it. The necessary genetic shifts of either motivation strengths, or threshold levels, or both together, will occur. The result is a new strain of domestic animal that is adjusted to the new condition. For such an adjusted animal we should be able to make the assumption that welfare is guar- anteed, just as we must make the same assumption about any wild animal in its natural habitat.

It follows that keeping animals in confined spaces is cruel only if inappropriate animals are kept in the confined spaces. After such animals have been allowed to adapt, then the cause of the cruelty has disappeared. It would, however, be cruel to continually alter environments such that animals were not able to keep pace through adaptation.

Tschanz (1978) wrote a very perceptive paper about behavioral norms and adaptation of animals to confined environments. He stated that the best measure of adaptation to an environment is reproduction, considered in its broadest sense, i.e., the ability of animals to maintain population numbers in that environment. We can all intuitively agree to this precept, and we applaud zookeepers who continue to alter the environments of their animals until they succeed in getting them to breed. In natural evolution as well, the measure of success is reproduction, considered in this broad sense. There is no doubt that, on the basis of this criterion, there are poultry and pigs that are already quite well adapted to intensive farming.

What Ethical Consequences Follow From Our Discussion?

It is impossible for humans to leave evolution to proceed by itself, i.e., completely free of their influence. Thus, there seems only one correct ethical decision: to direct the further evolution of life toward "the good" of the creation, i.e., of all of life. What this "good" is will have to be determined, and all men of goodwill should contribute to this definition of the ideal. I do not claim that science is our only tool in this task. Presumably all modes of human knowledge can contribute. My personal belief is that the use of reason will be a very important element in this effort. 
Whatever we may decide, it is clear that the relationship between humans and their domestic animals is merely a part of this reassessment of the totality of our relationships. In this limited area our task will be to define the environment in which our animals are to be kept. All relevant aspects, including economic efficiency, the health of animals, products, and keepers, and working conditions, should be considered. Then we should deliberately adapt our animals to the defined conditions through breeding. This procedure may have to be approached in stages if the environmental conditions aimed at are radically different from those to which the animals are now adapted. The evolutionary processes, if they are not obstructed or misdirected, must lead to such a degree of adaptation that welfare will have to be taken for granted, just as we can do no better than to take for granted the welfare of any wild animal in its natural habitat.

Many people have recognized that the correct design of the environment to fit an animal's current needs is a powerful method for improving animal welfare. $I$ agree that environmental modification is usually a quicker and more practical solution to a "welfare problem" than is genetic adaptation. We must guard, however, against assuming that the behavioral needs of animals, as they now exist, should be taken as inviolable. The needs of present domestic animals are different from those of their ancestors - they also differ among breeds - and there is no evidence that they have stopped changing in response to environmental changes. It seems rational to use genetic change, as well as environmental change, in our solution to "welfare problems."

The undoubted stress entailed in an adaptation period to a defined set of conditions may be justified as morally appropriate, provided that it is done in the light of the long-term rational plans we have made for the good of our domestic animals. Continual further adaptation of animals to ever-decreasing spaces, which might follow from simple considerations of economic gain, must, however, be recognized as cruel. This is a case where minimum standards of environment, rationally agreed upon by people of goodwill, after consideration of all relevant information, should be respected and enforced-where necessary, through legislation.

\section{Final Considerations}

Well-meaning defenders of the rights of animals (e.g., Teutsch, 1981) have argued against the morality of deliberate genetic adaptation as outlined by Zeeb and Beilharz (1980; see also Beilharz and Zeeb, 1981). I am convinced that such opposition arises from the different assumptions of Teutsch on the one hand and Zeeb and Beilharz on the other. I have deliberately taken a very broad perspective in the present article and have tried to show that genetic adaptation of domestic animals can only be a small part of mankind's overall guidance of future evolution. People of goodwill must assume moral responsibility for the future evolution of life on earth, for the good of all of life as well as for mankind. But, with Duncan (1980), let us determine to make our ethical decisions based on facts. Since it is life itself that we are considering, a thorough understanding of the facts of biology and its unifying theme of evolution are essential.

\section{References}

Anonymous (1978) Exotic diets and the infant, BrMed 1, 6716, April 1, 1978: 804-805.

Beilharz, R.G. and K. Zeeb (1981) Applied ethology and animal welfare, Appl Anim Ethol 7:3-10. 
Dawkins, M. (1976) Towards an objective method of assessing welfare in domestic fowl, Appl Anim Ethol 2:245254.

Dawkins, R. (1976) The Selfish Cene. Oxford University Press, Oxford, U.K.

Dobzhansky, T., F.J. Ayala, G.L. Stebbins and J.W. Valentine (1977) Evolution. Freeman, San Francisco.

Duncan, I.J.H. (1980) Can scientific research help in assessment of animal welfare? In Reviews in Rural Science IV, M. Wodzicka-Tomaszewska, T.N. Edey and J.J. Lynch, eds. Behaviour, University of N.E., Armidale, pp. 169-174.

Elton, C.S. (1958) The Ecology of Invasion by Animals and Plants. Chapman and Hall, London.

Lorenz, K. (1978) Vergleichende Verhaltensforschung. Springer, Vienna.

Manning, A. (1979) An Introduction to Animal Behaviour, 3rd ed., Arnold, London.

Mayr, E. (1963) Populations, Species and Evolution. Belknap, Cambridge, Massachusetts.

McBride, G. (1980) Adaptation and welfare at the man-animal interface. In Reviews in Rural Science IV, M. Wodzicka-Tomaszewska, T.N. Edey and J.J. Lynch, eds. Behaviour, University of N.E., Armidale, pp. 195198.

Rendel, J.M. (1967) Canalisation and Cene Control. Logos, London.

Ride, W.D.L. (1970) A Guide to the Native Mammals of Australia. Oxford University Press, Melbourne, Australia.

Shull, M.W., R.B. Reed, I. Valadian, R. Palombo, M. Thorne and J.T. Dwyer (1977) Velocities of growth in vegetarian preschool children, Pediatrics 60:410-417.

Singer, P. (1975) Animal Liberation. Discus, New York.

Teutsch, C.M. (1981) Neuere Entwicklungen in der ethischen Diskussion einer tiergerechten Nutztierhaltung.
Paper presented at the Meet. Int. Ges. fur Nutztierhaltung, Basel, Switzerland, January 22-23, 1981.

Tripp, J.H., D.E.M. Francis, J.A. Knight and J.T. Harries (1979) Infant feeding practices: a cause for concern. $\mathrm{Br}$ Med / 6192, September 22, 1979: 707-709.

Tschanz, B. (1978) Reaktionsnormen und Adaptation. In Das Tier im Experiment, W.H. Weihe, ed. Hans Huber, Bern, Switzerland.

Wickler, W. (1980) Sieben Thesen zum Tierschutz, Der Tierzuchter 32:248.

Zeeb, K. and R.G. Beilharz (1980) Angewandte Ethologie und artemässe Tierhaltung. Tierarztl Umschau 35: 603-610.

Zeuner, F. (1963) A History of Domesticated Animals. Hutchinson, London, U.K. 